\title{
El polifacético Itzhak Ben Rubí: un autor sefardí moderno
}

Itzhak Ben Rubí (1903-1977) fue uno de los más destacados escritores en lengua sefardí del siglo XX. Conocido especialmente como «Chimon-Chimon», pseudónimo que adoptara para su personaje humorístico, Ben Rubí hizo incursiones en todos los géneros de la literatura moderna escrita en judeoespañol: la poesía, la novela, el drama y el periodismo. Fue además el fundador del semanario en judeoespañol El Tiempo de Tel Aviv (1950-1967).

El presente artículo ofrece, por primera vez, una amplia biografía sobre Ben Rubí y una lista de todos sus escritos originales y traducciones: poemas, cuentos breves, novelas y piezas dramáticas conocidas e inéditas.

Palabras Clave: Itzhak Ben Rubí; judeoespañol; literatura en lengua sefardí; poesía en judeoespañol; novela en judeoespañol; teatro en judeoespañol; prensa sefardí; emisiones de radio en judeoespañol; humor.

The Multifaceted ItZHAK Ben Ruby: a MOdern SEPHARDI AUtHOR.- Itzhak Ben Ruby (1903-1977) was one of the most prominent Judeo-Spanish writers in the twentieth century. Best known as "Chimon-Chimon", pseudonym adopted by him for his humorous character, Ben Ruby dabbled in all genres of modern literature written in Judeo-Spanish: poetry, novel, drama and journalism. He was the founder and the director of El Tiempo (Tel Aviv 1950-1967) the political and literary weekly written in Judeo-Spanish.

This article provides, for the first time, a comprehensive biography of Ben Ruby and a list of all his known original writings and his literary translations: poems, short stories, novels and theater plays.

KeYwords: Itzhak Ben Ruby; Judeo-Spanish; Sephardic Literature; Judeo-Spanish Poetry; Judeo-Spanish Novels; Judeo-Spanish Theater; Journalism; Humor.

\footnotetext{
*hubgruss@inter.net.il
} 


\section{ITZHAK Ben Rubí: DATOS BIOGRÁFICOS}

Itzhak Ben Rubí nació en Seres (Grecia) el 25 de marzo de 1903 (KARPMAN 1978: 75). Sus padres, Bitti Ben Rubí y Lea (Lutcha) de Botón, dieron a su hijo una educación religiosa de tendencia liberal (TIDHAR 1955: 2.464) ${ }^{1}$. Tras las guerras balcánicas y el incendio de Seres en 1913 la familia se instaló en Salónica², donde Ben Rubí completó sus estudios en la Mission Laïque Française de la ciudad ${ }^{3}$. Sus estudios superiores los completó en el Cours Grands-Maîtres du Dessin de París, donde trabó una íntima relación con el dramaturgo francés Henry Marx (TIDHAR 1955: $2.464)^{4}$. De regreso a Salónica contrajo matrimonio en 1928 con Dora Camhy (Tidhar 1955: 2.499) .

Ben Rubí trabajó como jefe de administración del Banco de Salónica y durante los años 1928-1938 fue gerente de la empresa tabaquera AustroHellénique S.A. (KARPMAN 1978: 75) ${ }^{6}$. Las leyes de discriminación racial

${ }^{1}$ Su padre era farmacéutico; desciende de una familia de rabinos y médicos famosos. Su madre proviene de una familia de banqueros de Estambul.

2 Sobre las guerras balcánicas de 1912-1913 vid. Jelavich 1986.

3 Sobre la institución educativa Mission Laïque Française de Salónica ver Saloniki, 'Ir vaem beIsrael, p. 79. Ben Rubí hace mención de algunos de sus profesores: los eruditos en historia y pensamiento judío Mercado Covo y Yosef Nehamá, y el poeta Roger Millet sobre el cual escribe en El Tiempo 14/6/1962: «[...] professor de las escolas de la Mission Laique Francaise, licenciado en Letras y Dr. en filosofia, fue mi profesor al Lyceo de esta sivdad». Además anuncia la aparición de su libro: Roger Millet, Poemes saloniciens (Paris: Editions Louis Soulanges, 1961). El texto antes citado y los restantes que se aducen están en judeoespañol en caracteres latinos; respetamos su grafía.

4 Ben Rubí dedicó a su amigo una poesía en francés titulada Sonnet que se publicó en Salónica en la revista Pro Israel 53 (1/6/1924): 4. Henry Marx, de orientación sionista socialista, fue editor de la revista literaria y filosófica Connaître, en cuyo segundo fascículo publicó Ben Rubí uno de sus artículos (BEN RuBí 1972: 399).

5 Dora Camhi fue vice-presidenta de la agrupación sionista femenina Tziona (BEN RUBí 1972: 399) y de otras instituciones, y dirigió el periódico La mujer sionista. Ya en Israel trabajó en la rama femenina del partido laboral como directora del centro Hadar Ramatayim, Shikún Guiora (Davar 29/1/1963: 9). Fue colaboradora del semanario El Tiempo.

${ }^{6}$ La mayoría de los cinco mil obreros de la fábrica eran judíos. Entre los años 19391941 Ben Rubí retornó a su actividad comercial en el ramo del tabaco, industria muy desarrollada entre los judíos de Grecia. 
dictadas en Austria a partir de 1938 determinaron su destitución, lo que le llevó a buscar una solución laboral en la rama del comercio con la apertura de un negocio especializado en artículos de costura y de confección masculina?.

Ben Rubí fue miembro activo del movimiento sionista de Grecia, en el cual desempeñó funciones administrativas y directivas: miembro de la Asociación de Ĵ́venes Judiós de Salónica y presidente de la asociación sionista Tehiyá de Atenas; secretario general de la Liga Contra la Tuberculosis; presidente del comité del Hospital Psiquiátrico; director del Fondo Nacional (K.K.L.); y tesorero del Keren Hayesod (U.J.A.) de Grecia (KARPMAN 1978: 75).

Sus primeras obras literarias vieron la luz en la prensa judía de Salónica: en La Renacencia Judía / La Renassencia Djoudia en judeoespañol, y en Pro Israel, L'Opinion, Le Progrès, Le Canard y Connaître en francés (TidHAR 1955: 2.464; Romero 1979: 422). Entre 1940-1941 formó parte de las fuerzas armadas de Grecia, combatiendo en los frentes contra Albania e Italia. En abril de 1941 las tres potencias del Eje -Italia, Bulgaria y Alemania- invadieron Grecia, fraccionando el país en tres zonas .

Tras el desmantelamiento de las fuerzas armadas griegas, Ben Rubí prefirió no regresar a Salónica y se instaló en Atenas, zona bajo dominación italiana, pues consideró que la situación de los judíos en la capital sería más favorable. Su esposa y su hija Lilian lograron abandonar Salónica y reunirse con él. Cuando Atenas fue anexada al Comandatur y durante la ocupación nazi, la familia Ben Rubí encontró refugio junto a amigos griegos. Tras siete meses de clandestinidad en el seno de la familia Paschalidis, el padre, Andreas, comprendió que los Ben Rubí corrían peligro de ser denunciados y decidió encontrar una mejor alternativa. Mientras tanto, Lilian enfermó de hepatitis complicando la huida. El doctor Papastergiou acogió a la familia en su casa hasta el final de la contienda'.

${ }^{7}$ He recibido esta información inédita en octubre de 2011 de mano de Lilian Abastado, hija de Ben Rubí.

${ }^{8}$ La zona italiana fue tomada por los alemanes en septiembre de 1943.

9 Información remitida por Lilian Abastado, en octubre 2011. La Sra. Abastado ha relatado sus memorias en un libro titulado Lina's Notebooks: A document of Nazi occupation, publicado en griego en 1999. La familia Paschadilis y el doctor Papastergiou fueron reconocidos por Yad Vashem como «Justos de las naciones» en 1968. 
Tras la liberación en 1944 Ben Rubí se dedicó a la organización de contingentes de sobrevivientes del Holocausto hacia Palestina ${ }^{10}$. El 8 de agosto de 1945 emigró a Israel como director de 'Aliyat hanó 'ar (grupos de jóvenes inmigrantes) a cargo de doscientos cincuenta jóvenes griegos (TidHar 1955: 2.464). La familia echó raíces en Tel Aviv: durante los primeros meses compartió vivienda con el hermano de Dora Ben Rubí en la calle Bilu de Tel Aviv hasta que pasaron a una modesta casa en el vecindario 'Olei Yaván ('Inmigrantes de Grecia'). En los años sesenta del siglo XX el piso de los Ben Rubí de la calle Arlozorov 70 fue sede de una gran actividad cultural ${ }^{11}$. Ben Rubí fue miembro activo de la Haganá (cuerpo militar previo al establecimiento del Estado de Israel) y posteriormente, sirvió en las filas de la reserva del Ejército de defensa de Israel.

Ben Rubí se integró rápidamente en la vida cultural, social y política de Israel; fue miembro activo del Partido Laborista (Mapai) y de la Unión Obrera Israelí (Histadrut). Su nombre coronó las listas de oradores en las llamadas «Fiestas regionales de la Histadrut», en reuniones de esclarecimiento partidario y en charlas en francés y en judeoespañol que resumían los acontecimientos de la semana en poblaciones con un alto porcentaje de inmigrantes sefardíes ${ }^{12}$.

${ }^{10}$ La Sra. Frida Covo, sobreviviente de los campos de exterminio y residente en Tel Aviv me ha relatado que durante los meses de entrenamiento previos a su 'aliyá (emigración a Israel) Ben Rubí solía subirse a las mesas y levantar el ánimo a los desdichados con canciones y cuentos humorísticos.

${ }^{11}$ El Tiempo (8/1/1958: 2): «Los miembros del Grupo Dramatiko Arte son kordialmente invitados a asistir a la proxima reunion ke tendra lugar el Mierkoles $11 \mathrm{de}$ Julio del 1958 a las oras 19.30 en la kasa del haver I. Ben Rubi. LA DIREKSION».

${ }^{12}$ Los periódicos 'Al Hamišmar y Davar, órganos del partido, publicaban semanalmente los temas y los lugares de reunión y el nombre del conferenciante, señalando entre paréntesis la lengua en la que se llevaría a cabo el evento. Veamos a continuación algunos ejemplos. Davar (18/10/1948: 5): «Reunión de inmigrantes en la casa del inmigrante, Raanana, espaniolit: Itzhak Ben Rubí». Davar (28/4/1950: 1): «Reuniones por el $1^{\circ}$ de mayo, organizadas por el departamento de esclarecimiento de la comisión obrera, Hedera-Agrobank, I. Ben Rubí (spaniolit)». 'Al Hamišmar (4/1/1952: 7): «En el centro de cultura y esclarecimiento, las fiestas de la Histadrut, Netayim Maabará [campamento transitorio para inmigrantes], a las 15.00, Ben Rubí, conferencia y cantos». 'Al Hamišmar (5/3/1954: 5): «En Kfar Shalem A, en los establecimientos de la Histadrut, a las 11.00: sobre los acontecimientos de la semana - I. Ben Rubí, cantante - Nora Mechulam». Davar (3/12/1965: 8): «Reuniones. El día miércoles 8/12/65 a las 17.30, Kiryat Ono (en francés), conferencia a cargo de Itzhak Ben Rubí». Davar (19/9/1967: 8): 
En 1949 fue redactor del semanario del Partido Laborista Israelí (Mapai) El Avenir, Semanal de los Olim en judeoespañol y de su versión francesa L'Avenir (TidHar 1955: 2.464; Ares 1998: 30). Desde 1950 y hasta su clausura en 1967 fue editor en jefe del semanario en judeoespañol $E l$ Tiempo: Semanal Independiente Político y Literario de Tel Aviv (GAON 1965: 56; Harris 1994: 130; 147) ${ }^{13}$. Desde sus inicios en 1948 formó parte del equipo de La Boz de Israel, de Kol Israel, emisiones de radio en judeoespañol (Avenir 9/12/1949: 2; El Tiempo 21/4/1959: 2) ${ }^{14}$.

En el año 1954 fue delegado en el Segundo Congreso Mundial Sefardí que tuvo lugar en Jerusalén (El Tiempo 5/5/1954: 2). Durante los años 1956-1958 fue delegado del Keren Hayesod (U.J.A.) en Sudamérica. De sus experiencias en Cuba y en México dejó testimonio en su Impresiones de viaje, publicado en folletín coleccionable en el semanario El Tiempo núms. 386-397, entre las fechas 22/1/1958-9/4/1958 ${ }^{15}$. A principios de 1970 partió junto a su esposa Dora hacia Grecia, donde ejerció su profesión de periodista ${ }^{16}$.

Ben Rubí desarrolló una intensa actividad a favor de las relaciones entre Grecia e Israel, por lo cual fue condecorado con el título de Officier de l'Ordre de George I. Por su vasta actividad cultural y literaria fue distinguido en Bélgi-

«Actividades setiembre 1967 dependientes de "Olé le olé" [organización de inmigrantes veteranos voluntarios para el desarrollo social y cultural de los nuevos inmigrantes] el martes 25/9/67 en Hatzor, a las 16.00, Itzhak Ben Rubí - español». El último anuncio que he encontrado con la participación de Ben Rubí aparece en Davar el 13/10/1969.

${ }^{13}$ Colecciones casi completas de El Tiempo se conservan en la Biblioteca Nacional y en la Biblioteca del Instituto Ben-Zvi de Jerusalén, en el Archivo del Movimiento Obrero en Tel Aviv y en el Centro Naime y Yehoshua Salti en la Universidad de Bar-Ilán.

${ }^{14}$ El artículo «Comentarios de un oyente», publicado en Davar (29/8/1949: 22), habla sobre las transmisiones en judeoespañol y reproduce una fotografía de Ben Rubí.

15 Ya en el artículo «Letra de México», publicado en El Tiempo el 22/8/1956, Ben Rubí prometía registrar sus experiencias.

16 En León Zeldis «Historia de la Logia La Fraternidad No. 62 de Tel Aviv», http://www.thegoatblog.com.br/cadenafraternal/logiafraternidad.html (última consulta del 9/9/2013) leemos: «[...] Isaac Ben-Rubi, periodista y escritor en lengua judeoespañola, famoso en ese entonces por sus diálogos cómicos en la hora en ladino de Kol Israel. Un par de meses después de haber sido instalado en su cargo, el Hno: Ben-Rubi partió en un dilatado viaje a Grecia, donde ejerció su profesión de periodista». 
ca con la distinción de Caballero de la Orden del Mérito Civil y en España con La Cruz de Caballero del Mérito Civil (El Tiempo 30/11/1967: 2) ${ }^{17}$.

Pocos meses antes de su muerte la municipalidad de Tel Aviv le otorgó el título de Yekir Tel Aviv ('Ciudadano distinguido') ${ }^{18}$.

Ben Rubí falleció el 2 de noviembre de 1977; sus restos yacen en el histórico camposanto Nahalat Itzhak de Tel Aviv ${ }^{19}$. Tras la muerte de Ben Rubí, su esposa retornó a Grecia junto a su hija. La administración de la propiedad en la calle Arlozorov 70 de Tel Aviv quedó a cargo de un pariente quien, para conseguir mejores condiciones de renta, desalojó la biblioteca y el archivo personal de Ben Rubí, perdiéndose así un valioso material en judeoespañol.

\section{LA TRAYECTORIA LITERARIA DE ITZHAK BEN RUBÍ}

\subsection{En los medios de comunicación masiva: la radio y la prensa}

Itzhak Ben Rubí es un autor polifacético que no ha sido investigado seriamente hasta hoy (vid. Gruss 2013). Hizo incursiones en los diferentes géneros literarios: ensayo, poesía, novela, teatro, cuento y sátira periodística. Si bien su trayectoria literaria en Israel es poco conocida, no así su faceta de periodista, editor, locutor de radio y humorista, campo en el que fundamentalmente fue un observador de los acontecimientos cotidianos.

Ben Rubí se incorporó al género radiofónico en judeoespañol bajo la tutela de Itzhak Levy (1919-1977) (El Tiempo 21/1/1959: 2) ${ }^{20}$. El espacio

17 El Tiempo (30/11/1967: 2): «Abraham Elmaleh e Isaac Ben Rubí - En nombre del S. E. Jefe de Estado Español tengo el honor de admitiros en la Orden del Mérito Civil», palabras del Ministro Don Ramón Sáenz de Heredia en el Consulado General de España en Jerusalén. La Orden del Mérito Civil depende del Ministerio de Asuntos Exteriores de España; se concede a ciudadanos españoles o extranjeros que hayan realizado méritos de carácter civil.

18 Conmemorando el día de la Independencia de Israel, la ciudad de Tel Aviv distingue a doce de sus ilustres conciudadanos. Junto a Ben Rubí, compartieron tal honor el escritor Levin Kipnis, los artistas plásticos Ziona Tager y Yosef Zarisky, y el actor Yaacob ben Sirá.

19 Datos trasmitidos por la Hevrá Kadishá de Tel Aviv.

${ }^{20}$ Citaremos a algunos otros colaboradores: Yosef Abulafia, Yaacov Nitzani, Itzhak Molho, Itzhak Navón, Moshé Shaúl, Moshé Vital, Camelia Saba-Russo. 
radiofónico Aki vos Avla Chimon Chimon fue muy popular en Israel y en el extranjero, gracias a las emisiones en onda corta de Kol Israel ${ }^{21}$. Una selección de estos espacios fueron reelaborados y publicados por Ben Rubí en el año 1950 con el título Causerias humoristicas de Chimon Chimon. A la radio Kol Israel (Gruss 2011: 50-67). Esos espacios radiofónicos los llevaron a cabo Ben Rubí y otros colaboradores ${ }^{22}$. Ben Rubí dirigió también los debates en «La mesa redonda» de La Boz de Israel.

Según la Enciclopedia Tidhar (1955: 2.464), Ben Rubí fue el redactor del semanario del Partido Laborista Israelí (Mapai) El Avenir, Semanal de los Olim en judeoespañol y de su versión francesa. El periódico era distribuido gratuitamente entre los inmigrantes en los centros de absorción y en los campamentos de transición en distintos idiomas: ladino, yidish, francés, húngaro, búlgaro y rumano. En su mayoría los artículos del semanario se reducían a traducciones de periódicos publicados en hebreo y de otras fuentes, principalmente de aquellas sustentadas por el partido oficial (AREs 1998: 30). A partir del año 1950 y con el apoyo del Partido Laborista, Ben Rubí se convirtió en el editor en jefe del semanario en judeoespañol El Tiempo: Semanal Independiente Político y Literario de Tel

${ }^{21}$ En el periódico Davar (25/8/1948: 15 [en hebreo]) bajo la rúbrica «Comentarios de un espectador/oyente», publica algunas referencias sobre los programas de radio para inmigrantes. Junto a una fotografía de Ben Rubí podemos leer: «El productor de las transmisiones en judeoespañol, el Sr. Nisim Cohén, matiza los programas que incluyen noticias breves sobre el país, los campamentos provisionales de 'olim ['inmigrantes'], charlas sobre economía y desarrollo, vivienda y, circunstancialmente, una clase de hebreo y canciones. Entre los participantes: la locutora Tzipora Caner, el escritor Itzhak Ben Rubí, cuyo pseudónimo es "Chimón-Chimón 'olé ḥadáš", el poeta Yosef Alejandro-Pedro oriundo de Turquía». Algunas de las transmisiones de Chimon Chimon han sido registradas en youtube:

- Tio Daniel buska caza en Tel Aviv:

http://www.youtube.com/watch?v=ZIZJY5MmlTQ;

- Los Tikim: http://www.youtube.com/watch?v=r-cO_-P2Jmk;

- Shimon Shimon y su amigo milionario:

http://www.youtube.com/watch?v=q9GZqSLo4qM;

- El kamino para la luna: http://www.youtube.com/watch?v=IMAX4TePGxA;

- Shimon Shimon el pintor: http://www.youtube.com/watch?v=ZNcII2XNtRY;

- Shimon Shimon i el Djuez: http://www.youtube.com/watch?v=3D-kDK3Ke-s;

- El sinyor Badim: http://www.youtube.com/watch?v=iDMuuY30x-g.

22 Agradezco a Moshe Shaul el haberme entregado algunos guiones originales: Chimon Chimon a la Tzaada, 10/5/1968; Chimon Chimon y los gatos, 7/6/1968; El veto de Chimon Chimon, 6/9/1968; y Tio Daniel al night club, 12/7/1968. 
Aviv hasta su clausura en 1967 (SÁNCHEZ 1963: 4; GAON 1965: 56; HARRIS 1994: 130, 147).

Los artículos, firmados generalmente con su nombre o con sus iniciales I.B. o simplemente «La redaksion» incluyen reseñas de libros locales e internacionales, informes sobre las actividades de los sefardíes en Israel, reportajes de personalidades y de políticos relacionados con el mundo sefardí, informaciones de actualidad nacional e internacional. Los artículos de Ben Rubí sobre la realidad y la política del incipiente Estado, no carecieron de un análisis riguroso y agudo ${ }^{23}$.

Tras el seudónimo «Chimon Chimon» Ben Rubí escribió una columna semanal de trasfondo crítico-satírico para El Tiempo. La columna, titulada Opiniones de Chimon Chimon ocupó un lugar central en el periódico, en el ángulo derecho de la tercera página, enmarcado y con una discreta caricatura de su autor. Gran parte de dichas columnas fueron reeditadas en el periódico Șalom de Estambul.

Ben Rubí colaboró con varias revistas y periódicos en el extranjero: Anales Cervantinos de España, La Prensa Israelita y La Voz Sefaradí de México, y Șalom y La Vera Luz de Turquía ${ }^{24}$.

\subsection{Las novelas}

Ben Rubí es autor de varias novelas escritas originalmente en judeoespañol (Romero 1992: 243 y 258). La más conocida y considerada es $E l$ sekreto del mudo sobre la Segunda guerra mundial y la resistencia francesa. Algunos de sus capítulos transcurren en Salónica, otros en París

${ }^{23}$ Aunque El Tiempo se presenta como «semanario independiente» fue parcialmente financiado por el Partido Laborista Israelí: «Es verdad ke "El Tiempo" es un organo del partido Mapay, koza ke es natural i lejitimo, de ser i la porta-palavra del Mapay, pero por respekto a la verdad, devemos akodrar i relevar i los servisios del Mapay al elemento sefardi, de lingua judeo-espaniol, ke grasias a su jurnal "El Tiempo" se propaja, se sostiene, se enchalcha i se enkoraja [...]» (El Tiempo 24/1/1963).

${ }^{24}$ El artículo «Don Quijote y los judíos sefardíes» se publicó en Anales Cervantinos 2 (1952): 374-375. Podemos leer en El Tiempo 4/10/1966 una nota de Ben Rubí: «[...] Voz Sefardí una nueva i exelente revista mensual sefardí en espaniol dirijida por Shabetay Dinar i Abraham Elmaleh. Yo propio tendré el insigne honor de hacer parte del consejo de Redacción de "Voz Sefardí”». 
y en el campo de exterminio de Auschwitz. La novela tuvo una cierta repercusión contando con varias ediciones ${ }^{25}$ : fue traducida al francés por André Chédel y titulada Le muet d'Auschwitz (1973). La versión hebrea fue traducida por Yehuda Hazví en 1990 y permanece aún inédita.

Otros textos que vieron luz en folletines coleccionables en El Tiempo son los siguientes:

El sekreto del mudo: 8/4/1952-16/9/1953;

El apelo de la sangre: 12/5/1954-26/5/1954 ;

El amor ke mata: 14/12/1955-4/9/1956;

Impresiones de viaje: 22/1/1958-9/4/1958

La negrita del rio: 7/5/1958-8/7/1959;

El malogrado: 22/7/1959-3/2/1960² ;

Sangre, fuego y amor: 9/11/1961-31/1/1963 ${ }^{28}$;

${ }^{25}$ En la portada de la primera edición (1952) escribe: «En memoria de mi hermano Moise Bitti Ben Rubí y de su mujer Mairy (nassida Mechulam) desparessidos en el enferno nazi». La segunda edición vio la luz en Tel Aviv 1953. Según Refael (2008: 111), la novela recibió el premio Egit de Investigación de la Literatura del Holocausto, otorgado por la Unión General de Trabajadores de Israel, la Histadrut. Diversos autores han escrito comentarios y reseñas sobre el libro: Ovadia CAMHY en Le Judaisme Sephardi 25 (diciembre 1962: 1075); Rocío Moragas en La Voz de España de San Sebastián (23/2/1963); Alberto SÁnchez en Clavileño V (29/10/1954); Evangelina JARdiel PonCela en el periódico Pueblo de Madrid (El Tiempo 25/4/1963: 2); Itzhak R. MolHo en El Tiempo 27 (1.1954: 2), y Elena RoMERo en Sefarad 38 (1978). Además de los comentarios de Abraham Elmaleh, Yaakov Nitzani, Itzhak R. Molho, Baruh Uziel y Moshe D. Gaon adjuntos a la segunda edición de la novela (1953).

${ }^{26}$ Cuento publicado originalmente en aljamía, en Salónica y bajo el título Número 193 (Ben Rubí 1933; Gruss 2011). Según Ben Rubí la versión francesa vio la luz ese mismo año en Le Progres de Salónica y la versión en griego en Y Foni tu Israil de Atenas (BEN RuBí 1970).

${ }^{27}$ Según escribe Ben Rubí en el prólogo, la novela está inspirada en el manuscrito de R. de S. Moreno, que le fuera enviado por su hijo desde Nueva York. Trata sobre los amores del rico Pepo y la pobre muchacha Perla, con una interesante descripción de los bajos fondos de la ciudad de Salónica. En una carta dirigida a Michael Molho expresa su voluntad e ilusión: «[...] a mi juicio, de punto de vista folklóric "EL MALOGRADO" es la novela que mucho quiería ver publicada por un editor de España o de Argentina» (Ben Rubí 1961).

${ }^{28}$ A partir del 26 de abril de 1961 y el mismo día de su publicación (9/11/1961) se anuncia en las páginas de El Tiempo la aparición de un nuevo «romanso» de Ben Rubí: 
Ven mi vida: 8/10/1963-16/3/1965;

Almas puras: 23/3/1965-14/6/1966;

Eva: 4/10/1966-23/4/1967.

Por lo general las novelas pertenecen a un género melodramático, de contenido trivial, de una trama superflua, de tirada comercial y menos literaria que las anteriores nombradas ${ }^{29}$.

\section{El teAtro}

Algunos artículos y anuncios sobre funciones en el periódico El Tiempo hacen referencia a la vasta producción teatral de Ben Rubí, al reconocimiento de los ámbitos intelectuales de Israel y España, y a la compañía de teatro que personalmente dirigía.

Elena Romero (1992: 288) denomina a Ben Rubí «el ultimo de los mohicanos del teatro sefardí popular». Ben Rubí nos ha legado dos obras teatrales: Blum el judío o Simón Blum, escrita en Salónica en 1933, y Locos con seriedad, escrita en Tel Aviv en 1951 o 1952. Ambas obras son de contenido sionista y delatan las persecuciones nazis. Blum el judio es una comedia dramática en tres actos que se mantiene inédita (ROMERo 1979: 422-433) ${ }^{30}$. La portada del manuscrito dice que fue publicada por

«Serkanamente nuevo grande romanso». El nombre de la novela anunciada Dos mundos o Los dos mundos no aparece en ninguna bibliografía ni referencia lo que nos llevó a una búsqueda más profunda. La publicación de la novela anunciada para el 23/8/1961 fue postergada a raíz de la publicación de las memorias de Levy Tazartes y de Sam Levy. Una nota en El Tiempo del 5 de octubre de 1961, atribuida a una abonada de Grecia, resuelve la encrucijada: la abonada, con iniciales L.A., escribe: «Es ke se trata de algun sujeto de karakter politiko? Espero ke no. En este kavso es ke no se puede topar un titulo mas sugestivo?» La nota prosigue con la respuesta de la redacción: «La remarka de nuestra abonada fue bien resivida i la rengrasiamos. Por evitar kualkier mal-entendimiento roguimos al Sr Ben Rubi de dar un otro titulo a su romanso. El nuevo titulo sera: Sangre, fuego y amor». Uno de los anuncios resume su trama diciendo «Es un romanso inspirado de los anios eskuros de la okupasion nazista de la Europa».

29 En la contraportada de la segunda edición de El sekreto del mudo y tras la lista de publicaciones leemos: «En preparación: De misma sangre, romanso. Schenas israelianas, comedias y sketches», obras que no he conseguido localizar.

30 Agradezco a Elena Romero el haberme permitido fotocopiar el manuscrito de la obra. Según una información aparecida en El Tiempo (21/9/1953) el grupo de teatro Arte 
la A.J.J. (Asociación de Jóvenes Judiós) de Salónica. El autor declara en una carta dirigida a Iacob M. Hassán (de 3/4/1970) que la obra fue escrita como reacción a los sucesos políticos de la época y que su puesta en escena fue prohibida por decreto oficial del gobierno de Metaxas «pudiendo desacreditar un régimen o un jefe de estado extranjero». El manuscrito fue rescatado del horror nazi gracias a que Ben Rubí se lo entregó en 1937 a Yaacob Tzur, delegado de la Agencia Judía, durante su estancia en Salónica, quien lo guardó en Jerusalén (Ben Rubí 1970).

Locos con seriedad, pieza en tres actos, relata la ocurrente salvación de un grupo de judíos de las garras nazis entre los muros de un instituto psiquiátrico y las dificultades de los sobrevivientes en el incipiente Estado de Israel. En 1959 Alberto Sánchez publicó en la revista Insula un comentario sobre la obra (El Tiempo 22/7/1959). Con el título Metorafim birŝinut fue traducida al hebreo por Moshé Ghiora en 1952 y publicada por la Unión Obrera Israelí (Histadrut); se estrenó en Israel en 1953 en el Moshav Shave Zion con motivo de su quince aniversario. Según Yona Vang, director de la compañía dramática de la Histadrut: «Asistieron más de mil personas de los entornos i de diferentes lokalidades del paiz» $(E l$ Tiempo 21/9/1953: 3). La obra fue adaptada por Ester Camhi y publicada en México en 1958. Hemos tenido noticias de que la obra, en su versión española, fue puesta en escena recientemente en el Centro Deportivo Israelita de la ciudad de México ${ }^{31}$.

Según la poetisa Margalit Matitiahu, que fue durante muchos años integrante del grupo teatral «El Journal avlado de El Tiempo» y del grupo Arte, Ben Rubí tradujo del francés dos obras de Molière: El escaso (El avaro) y El médico a la fuerza, y El viaje del Sr. Perichon de Eugène

de Tel Aviv estuvo preparando la pieza para su futuro estreno, pero hasta hoy no hemos podido confirmar si la obra fue representada o no en Israel.

${ }^{31}$ En el programa del estreno en Shave Zion aparece la reseña de la obra, escrita en alemán, el nombre del director de escena y la pertenencia del grupo teatral. Contamos además con varios testimonios en la prensa israelí: el periódico 'Al Hamišmar del 15/12/1952 hace alusión al autor, a la publicación y a su traductor, y el periódico Omer del 4/1/1952 alaba las funciones de Ben Rubí. La obra Locos con seriedad se presentó en el Festival Habima el 1 de junio de 2000 por un grupo de preparatorianos (bachillerato en México) del Colegio Israelita de México (Idishe Shule fun Mexique) y los directores de la obra fueron Allan Smolensky y Roberto Torres Kleinberg, que adaptaron libremente el final a las necesidades de la comunidad. 
Labiche. Estos grupos teatrales auspiciados y dirigidos por Ben Rubí y similares, llevaron a cabo representaciones en los centros urbanos del Estado y también en lugares recónditos del país, reviviendo la lengua y las tradiciones dramáticas y musicales de los sefardíes ${ }^{32}$.

En una carta dirigida a Michael Molho, Ben Rubí (1961) declara haber «escrito para la Radio como 150 sketches que son breves comedias en un acto (escenas de la vida israelí)».

\section{LA POESÍA}

Ben Rubí tradujo numerosos poemas del francés, del griego y del hebreo $^{33}$. El semanario El Tiempo sirvió de puente esclarecedor entre los lectores ladino parlantes y la literatura hebrea moderna ${ }^{34}$. Las poesías traducidas por Ben Rubí en el semanario van acompañadas por las siguientes fórmulas: «adaptado al ladino por», «adaptacion libre en judeo-espaniol», «adaptasion judeo-espaniola por Itzhak Ben Rubi», «adaptasion en judeoespaniol por I. B», «transkrito en judeo espaniol por el autor». Por lo general las traducciones logran mantener el espíritu del poema original ${ }^{35}$.

El corpus de las poesías hebreas traducidas es canónico -Bialik, Tchernijowski, Fichman, Alterman, Goldberg- y su aparición está asociada, por lo general, a días de conmemoración nacional. El poema de

${ }^{32}$ El Tiempo 22/1/1958: «Los viejos i nuevos miembros del grupo dramatiko ARTE son kordialmente invitados a una reunion kon el haver I. Ben Rubi, el dia de Alhad 26/1/58, en nuestros buros Rehov Pinsker N² 2, Amidar 3, Kamerata 316, TE 26707».

33 Ben Rubí traduce y publica en El Tiempo (11/1/1951) uno de los poemas de Sión del poeta greco-judío Yossef Eliya (1901-1931); del francés traduce tanto un poema de Anatole France, Premio Nobel de literatura en 1921, como «El suenio de Yaakov» de Edmond Fleg (El Tiempo 22/9/1958 y 22/10/1963, respectivamente). Hemos encontrado un poema de Morris Rosenfeld, titulado «Mi chikito» en la versión de Ben-Rubí ( $E l$ Tiempo 21/3/1958), escrito originariamente en yidish.

34 En la Conferencia Internacional «Around the Point» (Universidad Bar-Ilan, 1719/12/2012) me ocupé ampliamente de «La página literaria y la literatura hebrea moderna en el semanario El Tiempo».

35 Encabezando la poesía «En la guardia» leemos (El Tiempo 5/5/1954) lo siguiente: «Nuestro redaktor en kapo, el escritor Itzhak Ben Rubi, autor del romanso "El secreto del mudo" nos da aqui una adaptacion libera de un poema de Chaul Tchernihovski, en el kual el respekto la idea generala i el rytmo del grande poeta». 
Jacob Fichman «El Ghetto [Kemado] de Varsovia» se publicó dos veces el día de la conmemoración por las víctimas del Holocausto (El Tiempo 12/4/1956 y 27/4/1965). En 1965, junto al poema de Fichman, Ben Rubí publica uno suyo: «Eskutcha mi hermano» (El Tiempo 6/4/1962 y $27 / 4 / 1965)^{36}$. Algunas poesías del muy famoso poeta Natan Alterman se publicaron en vísperas del Día de la Independencia: «Eviva Capitan» (El Tiempo 14/2/1950), «Notche de guerra» (El Tiempo 30/11/1950), «El plato de plata» (El Tiempo 23/4/1958 y 4/5/1965) ${ }^{37}$. Ben Rubí también publicó un poema suyo titulado «Oh, Patria!» dedicado «a la madre israeli» (El Tiempo 15/6/1965).

La poesía más antigua que he encontrado es un soneto escrito en francés dedicado a Henry Marx (Ben Rubí 1924). Otras poesías suyas son Yerushalayim (El Tiempo 2/5/1963); El enkontro (El Tiempo 13/8/1952) -republicada como El encuentro (El Tiempo 7/7/1964)-, dedicada a Teodoro Herzl.

Un grupo de admiradores publicó en México, posiblemente en 1956 ó 1957, un cuadernillo de poesías titulado Poemas ${ }^{38}$, que contiene los siguientes poemas: Yerushalayim; Entonces, hijo mío, serás Judio -junto con su versión francesa Alors, tu seras un Juie, mon fils-; La voz de Hertzel a la Tierra de Israel; Respuesta de la Tierra de Israel ${ }^{39}$; y el poema sobre el Holocausto, Escucha mi hermano.

Ben Rubí escribió también algunas poesías de contenido humorístico, al estilo de las conocidas tradicionalmente como las «coplas del felek»;

${ }^{36}$ Reproducido por Isaac Jack Levy (1989: 64-70) y analizado por Shmuel RefaEL (2008: 111-114 y 205-207).

37 En El Tiempo del 23/3/1962, en un artículo dedicado a Natan Alterman se mencionan las siguientes obras: Kineret, Kineret; Estreyas, afuera; La alegria de los proves; La Septima columna I, II; Ir Hayona (La sivdad de la paloma); y las poesías Noche de guerra, Eviva Kapitan [frag.], Magasch Hakesef ('El plato de plata') [frag.] y Ohel Sayarim ('La tienda de los exploradores') [frag.].

38 Ben Rubí Poemas (Méjico), en donde en Nota se dice: «Los poemas de este folleto fueron libremente adaptados en castellano con la amable colaboración de Jana Kleinburg y León Gateño».

39 Una glosa explicativa anticipa las dos poesías en honor a Hertzl: «(En ocasión del traslado de los restos mortales del Doctor Teodoro Hertzel a Israel, 17 de agosto de 1949)». Las poesías coinciden con la ya citada El enkontro, publicada en El Tiempo $(13 / 8 / 1952$ у $7 / 7 / 1964)$. 
Ben Rubí adoptó esta cuenca poética para la crítica social y política sobre el Estado de Israel. Es sumamente interesante ver que para estos poemas prefirió su pseudónimo «Chimon-Chimon» y no su nombre. Veamos a continuación algunos ejemplos: Oh, tu sevoya (El Tiempo 21/2/1952), A la tchintura (El Tiempo 28/2/1952), Los platikos de Purim (El Tiempo 13/3/1952 y 8/3/1966), Suetos (El Tiempo 24/9/1952), La Agada de la Liberacion (El Tiempo 28/4/1954), Vos espero (El Tiempo 25/8/1954) y Plano sekreto (El Tiempo 12/4/1956).

Durante los años cincuenta su nombre tuvo una cierta repercusión en medios literarios de España y México. La escritora española Rocío Moragas confiesa haber descubierto a Ben Rubí a través de las publicaciones de la revista Sefarad y Anales Cervantinos de Madrid y lo considera uno de los escritores populares de Israel, como poeta, dramaturgo y novelista (El Tiempo 4/4/1963).

Ben Rubí alentó y encauzó a jóvenes escritores sefardíes a escribir en lengua judeoespañola; organizó «konkorsos de poezia» con modestos premios y otorgando a los ganadores un espacio para la publicación de sus poesías $^{40}$. Es así como en El Tiempo vieron la luz versos de Rica Sadikario (24/2/1954), Margalit Matityahu (30/12/1953, 6/1/1954 y 16/1/1957), Haim Hassan (28/2/1952 y 23/3/1952), Elie Hassid (10/3/1954), Joseph Behar (15/5/1952), David Menache (9/4/1953 y 5/12/1956) y «Una Madre Judía», pseudónimo (15/5/1952).

\section{El humOR DE Ben Rubí}

Ben Rubí confiesa ser el bisnieto del humorista Manuel Alatini de Salónica, de quien, por lo visto, heredó su elocuencia y su buen tino. Sus primeras expresiones en este estilo vieron la luz en la columna humorís-

${ }^{40} \mathrm{El}$ anuncio del primer concurso dice: «Numerosos son los lektores ke mos mandan poezias. Esto es una prova ke la literatura atira a nuestros keridos lektores. Kijiendo enkorajarlos en este kamino, detchidimos de organizar "UN KONKORSO DE POEZIA" onde partichiparan todos sin eksepsion [...] AVANTAJES. 1) La poezia ke obtenera nuestro premio sera publikada en nuestro semanal kon la foto de su autor. 2) El premio konsistera en un bilieto de Loteria del "Mifal Hapais" y un abonamiento de un anio a nuestro periodiko» (El Tiempo 14/2/1952). El segundo concurso se anunció en El Tiempo del 15/4/1952. 
tica «Sonrisa Sionista» del periódico La Renacencia Judía (GAon 1965: 118; Ben Rubí 1972: 340). Según el propio Ben Rubí, «los evenimientos de Alemania» lo llevaron a abandonar su participación en el periódico humorístico Canard «para consagrarse enteramente a travajos más serios y más educativos de punto de vista sionista y de dignidad humana» (BEN Rubí 1970).

Ya en Israel fue el responsable de la columna «Humour» del semanario El Avenir (13/4/1950: 2).

Durante el primer año del semanario El Tiempo los apartados de humor no fueron constantes. Los aparecidos el 13, 20 y 27 de julio de 1950 se denominan «Sonrizas», mientras que el 21 de julio de 1950, el 4 y el 11 de enero de 1951 y el 15 de febrero de 1951 figuran bajo la rúbrica «Humor». No llevan autoría, aunque se trasluce el estilo de Ben Rubí. A partir de enero de 1952 comienza una serie de tiras humorísticas, las Humoreskas, «Anekdotas eskojidas o komposadas por Chimon-Chimon» y publicadas por lo general en la segunda página del semanario. Con el tiempo (8/8/1959) estos pasatiempos humorísticos cedieron lugar a las Opiniones de Chimon Chimon, una columna satírica que supo reflejar la situación política y social del mundo y de Israel hasta la clausura del periódico el 23 de abril de 1967.

Bibliografía citada

Abastado, Lina (1999): Lina's Notebooks: A document of Nazi occupation (Thessaloniki: Kapani) [en griego].

Alterman, Natán (1950): «Eviva Capitan», El Tiempo 14/2/1950, 2.

Ares, Berta (1998): «Ladino Newspapers in Early Israeli State», Kesher 24, 28 33 [en hebreo].

Ben Rubí, Itzhak (1924): «Sonnet», Pro Israel 53 (Salonique, 29 Iyar 5684), 4.

- (1933): «Número 193», Études Sionistes 2 (Editée par L'Association de Jeunes Juifs, Salonique, Setembre 1934), 16-21.

- (ed.) (1950-1967): El Tiempo, Semanal Independiente Político y Literario de Tel Aviv (Tel-Aviv). 
- (1950): Causerias humoristicas de Chimon Chimon (Tel-Aviv).

— (1950): «Notche de guerra», El Tiempo 30/11/1950, 2.

— (1952): «Don Quijote y los judíos sefardíes», Acer 2, 374-375.

— (1956): Impresiones de viaje (Tel-Aviv).

- (1958): «El plato de plata», El Tiempo 23/4/1958, 2 (reeditado en El Tiempo 4/5/1965, 2).

- (1959): El Malogrado (Tel-Aviv).

— (1961): Carta dirigida a Michael Molho desde Tel Aviv el 28/6/1961 (Biblioteca Hassán-Romero, Madrid).

— (1962): «Escucha mi hermano», El Tiempo 6/4/1962, pág. 3 (reeditado en El Tiempo 27/4/1965, 2).

— (1970): Carta dirigida a Iacob M. Hassán desde Atenas el 3/4/1970 (Biblioteca Hassán-Romero, Madrid).

— (1972): «Agudat Ŝe‘irim A.J.J.», en A. Recanati (ed.), Źijrón Saloniki (TelAviv), vol. I, 398-400.

Fichman, Jacob (1951): «El Ghetto de Varsovia», El Tiempo 4/1/1951, 2 (reeditado en El Tiempo 12/4/1956, 2; y 27/4/1965, 2).

Gaon, Mošé David. (1965): A Bibliography of the Judeo-Spanish Press (Jerusalem: Ben Zvi Institute-Hebrew University) [en hebreo].

Gruss, Susy (2011): «Un selaniclí en Tel Aviv», en Rena Molho, Hilary Pomeroy y Elena Romero (eds.), Judeo Espagnol: Textos satíricos judeoespañoles: de salonicenses o sobre salonicenses (Thessaloniki: Ets Ahaim Foundation), 50-67.

Gruss, Susy (2013): «El semanario El Tiempo de Tel Aviv como vehículo de la integración del inmigrante sefardí», en Rosa SÁNCHEZ y Marie-Christine Bornes VAROL (eds.), La presse judéo-espagnole, support et vecteur de la modernité (Istanbul: Libra), 85-99.

HARris, Tracy (1994): Death of a Language: the history of Judeo-Spanish (Newark: University of Delaware Press).

Jelavich, Barbara - Jelavich, Charles (1986): The Establishment of the Balkan National States, 1804-1920 (Seattle: University of Washington Press).

Karpman, I. J. (ed.) (1979): Who is Who in World Jewry (Tel-Aviv: Olive Books of Israel). 
LeVy, Isaac Jack (2000): And the World Stood Silent: Sephardic Poetry of the Holocaust (Urbana: University of Illinois Press).

NitZANI, Yaacov (1961): «El escritor, el periodista y el artista Itzhak Ben Rubí», Mahberet 10, 48-49.

Refael, Shmuel (2008): Un grito en el silencio: La poesía sobre el Holocausto en lengua sefardí. Estudio y Antología (Barcelona: Tirocinio).

Romero, Elena (1978): Reseña a: I. Ben Rubi, Le muet d'Auschwitz, Sefarad 38, 386-387.

— (1979): El teatro de los sefardíes orientales (Madrid: CSIC), 3 vols.

- (1992): La creación literaria en lengua sefardí (Madrid: Mapfre).

S/N. (1959): «Radio Kol Israel en Judeo-Espaniol: sus colaboradores, sus programas, sus proyectos», El Tiempo 21/4/1959, 2.

Saloniki. 'Ir vaem beIsrael / Salonique. Ville-Mère en Israël (1967) (JerusalemTel Aviv: Centre de Recherches sur le Judaïsme de Salonique) [en hebreo].

SÁNCHEZ, Alberto (1959): «Locos con seriedad», Insula 14:151, pág. 2 del suplemento.

- (1963): «Literatura sefardí en el nuevo Estado de Israel». Tirada aparte de El Ingenioso Hidalgo, Año III - No 8 (Madrid: Publicaciones del Instituto Nacional de Enseñanza Media «Cervantes»), 1-7.

TIDHAR, David (1955): Encyclopedia of the Founders and Builders of Israel, vol. 6, 2.464, en http://www.tidhar.tourolib.org/tidhar/view/6/2464.

Zeldis, L. «Historia de la Logia La Fraternidad No. 62 de Tel-Aviv», en http://www.thegoatblog.com.br/cadenafraternal/logiafraternidad.html.

Recibido: $24 / 01 / 2015$

Aceptado: 06/07/2015 